\title{
The Antioxidation and Antiproliferation Activity of New Flavonoids from the Leaves and Stems of Cinnamomum reticulatum Hayate
}

\author{
Chi-Ming Liu ${ }^{1}$, Hung-Chun Yeh², Song-Chih Huang ${ }^{3}$, Cheng-Ta Li ${ }^{2 *}$ and Chung-Yi Chen ${ }^{2 *}$
}

${ }^{1}$ Department of Nursing, Tzu Hui Institute of Technology, Pingtung County, 92641 Taiwan

${ }^{2}$ Department of Nutrition and Health Sciences, School of Medical and Health Sciences, Fooyin University, Kaohsiung, 83102 Taiwan

${ }^{3}$ Department of Creative Product Design, College of Design, Ling Tung University, Taichung, 40852, Taiwan

\begin{abstract}
Cinnamoum reticulatum Hayata (Lauraceae) is an indigenous tree species in Taiwan. In this study, we further isolated the two flavonoids compounds kaempferol-3-O-(2",4"-di-E-p-coumaroyl)- $\alpha$-L-rhamnopyranoside (1) and kaempferol-3-O-(3",4"-di-E-p-coumaroyl)- $\alpha$-L-rhamnopyranoside (2) from the leaves and stems of $C$. reticulatum Hayate. The phytochemical characteristics, antioxidant and cytotoxic activities of the two compounds were evaluated. Kaempferol-3-O-(2",4"-di-E-p-coumaroyl)-a-L-rhamnopyranoside (1) and kaempferol-3-O-(3",4"-di-E-p-coumaroyl)- $\alpha$ L-rhamnopyranoside (2) have antiproliferation activity in lung cancer cell line (A549 and $\mathrm{NCl}-\mathrm{H} 460$ ) and breast cancer cell line (MCF-7 and MDA-MB-231). However, (1) displays better antioxidant activity than (2). Our results showed that the two flavonoids from $C$. reticulatum might have good potential for further development as chemoprevention or antioxidant remedies.
\end{abstract}

Keywords: Cinnamoum reticulatum Hayata; Lauraceae; Flavonoids; Antioxidant

\section{Introduction}

The Cinnamomum species have used in folk medicine. Cinnamomum species have many active chemical compounds with anti-oxidation, anti-cancer, anti-infection and anti-inflammatory activities [1,2]. Cinnamoum reticulatum Hayata (Lauraceae) is an evergreen tree, a tree native to Taiwan. Previous studies, we have isolated compounds including reticuol, isoreticulide, 4-hydrox-3methoxyphenethyl derivate, reticumanone, reticuone, cinnaretamine and isoobtusilactone A from the stems and leaves of Cinnamomum reticulatum [3-5].

Flavonoids are a group of nature compounds with phenolic structure and common characteristics C6-C3-C6 skeleton consisting of two benzene rings. Flavonoids possess anti-oxidation, anti-cancer, hepatoprotective, anti-inflammatory activities [6$8]$. In the current study, we further isolated reticuol and two new flavonoids compounds kaempferol-3-O-(2",4"-di-E-p-coumaroyl)a-L- rhamnopyranoside (1) and kaempferol-3-O-(3",4"-di-Ep-coumaroyl)-a-L-rhamno- pyranoside (2) from the leaves of Cinnamomum reticulatum (Figure 1). In the current study, we will examine the anti-oxidation and anti-proliferation activity of the two new flavonoids compounds in cancer cells.

\section{Materials and Methods}

\section{Extraction and isolation}

The air-dried leaves of Cinnamomum reticulatum Hay $(3.4 \mathrm{~kg})$ were extracted with $n$-hexane $(30 \mathrm{~L} \times 5)$ and $\mathrm{CHCl}_{3}(30 \mathrm{~L} \times 5)$ at room temperature and an $n$-hexane extract $(43.5 \mathrm{~g})$ and a $\mathrm{CHCl}_{3}$ extract $(151.5 \mathrm{~g})$ were obtained upon concentration under reduced pressure. The $\mathrm{CHCl}_{3}$ extract (151.5 g) was chromatographed over silica gel (800 g, 70-230 mesh) using $n$-hexane $/ \mathrm{CHCl}_{3} / \mathrm{MeOH}$ mixtures as eluents to produce five fractions. A part of fraction $4(10.62 \mathrm{~g})$ was subjected to silica gel chromatography by eluting with $\mathrm{CHCl}_{3}: \mathrm{MeOH}(60: 1)$, enriched with $\mathrm{MeOH}$, to furnish five fraction (4-1 4-5). Fraction 4-3 $(1.89 \mathrm{~g})$ was further purified on a silica gel column using $\mathrm{CHCl}_{3}-\mathrm{MeOH}$ mixtures to obtain reticuol $(6 \mathrm{mg})$, kaempferol-3-O-(2",4"-di- $E-p$ coumaroyl)- $\alpha$-L-rhamnopyranoside (1) (21 mg) and kaempferol-3-O(3",4"-di-E-p-coumaroyl)- $\alpha$-L-rhamnopyranoside (2) (15 mg).

\section{Cell culture}

Human lung cancer and human breast cancer cell lines A549, NCI-H460 MCF-7 MDA-MB231 were obtained from BCRC (Bioresoure Collection and Research Center, Hsinchu, Taiwan). They were cultured in MEM medium supplemented with $10 \% \mathrm{FBS}$, $10 \mu \mathrm{g} / \mathrm{mL}$ of penicillin, $10 \mu \mathrm{g} / \mathrm{mL}$ of streptomycin and $0.25 \mu \mathrm{g} / \mathrm{mL}$ of amphotericin $\mathrm{B}$. The cells were maintained in a humidified incubator at $37^{\circ} \mathrm{C}$ in $5 \% \mathrm{CO}_{2}$.

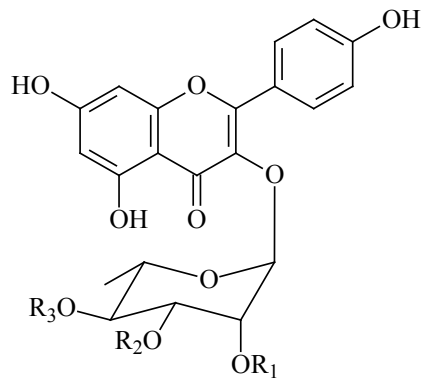<smiles>CC(C)(C)C(=O)/C=C/c1ccc(O)cc1</smiles>

$$
\begin{array}{llll} 
& \mathrm{R}_{1} & \mathrm{R}_{2} & \mathrm{R}_{3} \\
1 & \mathrm{EC} & \mathrm{H} & \mathrm{EC}
\end{array}
$$$$
2 \text { H } \quad \text { EC } \quad \text { EC }
$$

kaempferol-3-O-(2",4"-di-E-p-coumaroyl)- $\alpha$-L-rhamnopyranoside (1) kaempferol-3-O-(3",4"-di-E-p-coumaroyl)- $\alpha$-L-rhamnopyranoside (2)

Figure 1: The chemical structure of two flaonoids

*Corresponding authors: Chung-Yi Chen, Department of Nutrition and Health Science, School of Medical and Health Sciences, Fooyin University, Ta-Liao District, Kaohsiung, 83102 Taiwan, Tel: +886-7-781-1151 (ext. 6200); Fax: +886-7783-4548; E-mail: xx377@fy.edu.tw

Cheng-Ta Li, Department of Nutrition and Health Science, School of Medical and Health Sciences, Fooyin University, Ta-Liao District, Kaohsiung, 83102 Taiwan, E-mail: chtali2002@yahoo.com.tw

Received January 29, 2015; Accepted February 23, 2015; Published February 25, 2015

Citation: Liu CM, Yeh HC, Huang SC, Li CT, Chen CY (2015) The Antioxidation and Antiproliferation Activity of New Flavonoids from the Leaves and Stems of Cinnamomum reticulatum Hayate. Med chem 5: 064-066. doi:10.4172/2161 0444.1000244

Copyright: ( 2015 Liu CM, et al. This is an open-access article distributed under the terms of the Creative Commons Attribution License, which permits unrestricted use, distribution, and reproduction in any medium, provided the original author and source are credited. 


\section{Cell viability assay-XTT assay}

The XTT (2,3-Bis-(2-methoxy-4-nitro-5-sulfophenyl)-2Htetrazolium-5- carboxanilide) assay was used to determine cell viability and proliferation. The cell lines were seeded in 96-well culture plates $\left(1 \times 10^{4}\right.$ cells/well). XTT were obtained from Sigma-Aldrich $(\mathrm{GmbH}$, Sternheim, Germany). After seeding cells for $24 \mathrm{~h}$, various different concentrations of compounds were added. After the treatment, the medium was replaced with fresh medium without drugs. XTT reagent was added to each well and cultured for 3 hours. The optical density (OD) values of the supernatant were measured at $492 \mathrm{~nm}$ and $690 \mathrm{~nm}$ (reference wavelength). All experiments were repeated at least three times.

\section{Determination of DPPH radical scavenging capacity}

DPPH is an abbreviation for an organic chemical compound 2,2-diphenyl-1-picrylhydrazyl. It is a dark-colored crystalline powder composed of stable free-radical molecules. The mechanism of its radical scavenging activity is the antioxidant transfer of an electron or a hydrogen atom to DPPH. DPPH were obtained from Sigma-Aldrich (GmbH, Sternheim, Germany).The measurement of radical scavenging properties of compounds was carried out according to the method of Blois [9]. Various concentrations of the three compounds were added to $0.1 \mathrm{M}$ of stable DPPH $(60 \mu$ mole/L) solution. When DPPH reacts with hydrogen-donating antioxidant, it is reduced, resulting in a decrease in absorbance at $517 \mathrm{~nm}$. The analyzed time interval was $10 \mathrm{~min}$ per point, up to $30 \mathrm{~min}$ by using UV-Vis spectrophotometer (Jasco V-530, Japan Servo Co.Ltd., and Tokyo, Japan). Vitamin C was used as a positive control. Measurements were taken in triplicate. The $\mathrm{DPPH} \bullet$ radical scavenging activity (\%) was determined as: $1-[(\mathrm{A}$ $\left.\left.-\mathrm{A}_{\text {sample }}\right) / \mathrm{A}_{\text {control }}\right] \times 100$.

\section{Reducing power}

Briefly, various concentrations of test samples were mixed with 67 $\mathrm{mM}$ phosphate buffer $(\mathrm{pH} 6.8,0.085 \mathrm{~mL})$ and $20 \%$ potassium ferric cyanide $\left[\mathrm{K}_{3} \mathrm{Fe}(\mathrm{CN})_{6}, 2.5 \mu \mathrm{L}\right)$ The mixture was incubated at $50^{\circ} \mathrm{C}$ for $20 \mathrm{~min}$, and trichloroacetic acid $(10 \%, 0.16 \mathrm{~mL})$ was then added to the mixture that was then centrifuged for $10 \mathrm{~min}$ at $3000 \mathrm{~g}$. The upper layer of the solution $(75 \mu \mathrm{L})$ was mixed with $2 \% \mathrm{FeCl}_{3}(25 \mu \mathrm{L})$, and the absorbance was measured with a 96 -well plate spectrophotometer at $700 \mathrm{~nm}$. 3-tert-butyl-4-hydroxyanisole (BHA) was used as a positive control. A higher absorbance demonstrates a higher reductive capability.

\section{Statistical analysis}

All experiments were carried out at three times and at least triplicate. The results were expressed as the average of the mean values \pm standard deviation (SD). Analysis of the data was done with SigmaPlot software (Version 8.0, SPSS Scientific, and Chicago, IL, USA) and SigmaStat (Version 2.03, SPSS Scientific) run on an IBM-compatible computer.

\section{Results}

\section{Spectra results}

The structure of compounds 1 and 2 were elucidated using Nuclear Magnetic Resonance Spectroscopy (NMR), 1-DNMR and 2-DNMR.

Ka empferol-3-O- (2", 4" - di- E- $p$ - cou maroyl ) - $\alpha$ - L rhamnopyranosid (1)

Yellow powder; UV $\lambda_{\text {max }}(\mathrm{MeOH}, \log \varepsilon) 351$ (4.7), 256 (4.8), 208 (5.1) nm; IR (KBr) $v_{\max } 3377,1687,1655,1604,1513 \mathrm{~cm}^{-1} ;{ }^{1} \mathrm{H}$ NMR $(400$ $\left.\mathrm{MHz}, \mathrm{CD}_{3} \mathrm{OD}\right) \delta 0.87(3 \mathrm{H}, \mathrm{d}, J=5.8 \mathrm{~Hz}), 3.34(1 \mathrm{H}, \mathrm{dq}, J=9.8,6.2 \mathrm{~Hz})$,
$4.19(1 \mathrm{H}, \mathrm{dd}, J=3.5,9.8 \mathrm{~Hz}), 4.99(1 \mathrm{H}, \mathrm{t}, J=9.8 \mathrm{~Hz}), 5.57(1 \mathrm{H}, \mathrm{br} \mathrm{s}), 5.76$ $(1 \mathrm{H}, \mathrm{br} \mathrm{s}), 6.22(1 \mathrm{H}, \mathrm{br} \mathrm{s}), 6.34(1 \mathrm{H}, \mathrm{d}, J=15.9 \mathrm{~Hz}), 6.40(1 \mathrm{H}, \mathrm{d}, J=15.5$ $\mathrm{Hz}), 6.42$ (1H, br s), 6.84 (each $1 \mathrm{H}, \mathrm{d}, J=8.2 \mathrm{~Hz}), 6.85$ (each $1 \mathrm{H}, \mathrm{d}, J=8.2$ $\mathrm{Hz}), 7.05$ (each $1 \mathrm{H}, \mathrm{d}, J=7.4 \mathrm{~Hz}$ ), 7.53 (each $1 \mathrm{H}, \mathrm{d}, J=7.4 \mathrm{~Hz}$ ), 7.54 (each $1 \mathrm{H}, \mathrm{d}, J=7.6 \mathrm{~Hz}), 7.64(1 \mathrm{H}, \mathrm{d}, J=15.5 \mathrm{~Hz}), 7.74(1 \mathrm{H}, \mathrm{d}, J=15.9 \mathrm{~Hz}), 7.85$ (each $1 \mathrm{H}, \mathrm{d}, J=7.6 \mathrm{~Hz}$ ); FABMS $m / z 725[\mathrm{M}+\mathrm{H}]^{+}$.

\section{Kaempferol-3-O-(3",4"-di-E-p-coumaroyl)- $\alpha$-L- rhamnopy- ranoside (2)}

Yellow powder; UV $\lambda_{\max }(\mathrm{MeOH}, \log \varepsilon) 351$ (4.7), 256 (4.8), 208 (5.1) nm; IR (KBr) $v_{\max } 3377,1687,1655,1604,1513 \mathrm{~cm}^{-1} ;{ }^{1} \mathrm{H}$ NMR $\left(400 \mathrm{MHz}, \mathrm{CD}_{3} \mathrm{OD}\right) \delta 0.85(3 \mathrm{H}, \mathrm{d}, J=6.3 \mathrm{~Hz}), 3.4(1 \mathrm{H}, \mathrm{m}), 4.44(1 \mathrm{H}, \mathrm{m})$, $5.20(1 \mathrm{H}, \mathrm{t}, J=10.1 \mathrm{~Hz}), 5.45(1 \mathrm{H}, \mathrm{dd}, J=3.2,10.1 \mathrm{~Hz}), 5.60(1 \mathrm{H}, \mathrm{d}, J=1.3$ $\mathrm{Hz}), 6.00(1 \mathrm{H}, J=6.3 \mathrm{~Hz}), 6.21(1 \mathrm{H}, \mathrm{d}, J=16.0 \mathrm{~Hz}), 6.24(1 \mathrm{H}, \mathrm{d}, J=2.0$ $\mathrm{Hz}), 6.33(1 \mathrm{H}, \mathrm{d}, J=16.0 \mathrm{~Hz}), 6.46(1 \mathrm{H}, \mathrm{d}, J=2.0 \mathrm{~Hz}), 6.73($ each $1 \mathrm{H}, \mathrm{d}$, $J=8.6 \mathrm{~Hz}$ ), 6.86 (each $1 \mathrm{H}, \mathrm{d}, J=8.6 \mathrm{~Hz}), 7.09($ each $1 \mathrm{H}, \mathrm{d}, J=8.7 \mathrm{~Hz}), 7.43$ (each $1 \mathrm{H}, \mathrm{d}, J=8.6 \mathrm{~Hz}), 7.44$ (each $1 \mathrm{H}, \mathrm{d}, J=8.6 \mathrm{~Hz}), 7.56(1 \mathrm{H}, \mathrm{d}, J=16.0$ $\mathrm{Hz}), 7.65(1 \mathrm{H}, \mathrm{d}, J=16.0 \mathrm{~Hz}), 7.82($ each $1 \mathrm{H}, \mathrm{d}, J=8.7 \mathrm{~Hz}$ ); FABMS $m / z$ $725[\mathrm{M}+\mathrm{H}]^{+}$.

\section{Biological activity}

$\mathrm{IC}_{50}$ is a measure of the effectiveness of a drug in inhibiting biological or biochemical function. In the present study, the antiproliferation activity of the two compounds was determined by XTT assay and the results were presented in Table 1 . Based on the $\mathrm{IC}_{50}$ value of two compounds, kaempferol-3-O-(3",4"-di-E- $p$-coumaroyl)$\alpha$-L-rhamnopyranoside (2) has better anti-proliferation activity than kaempferol-3-O-(2",4"-di-E-p-coumaroyl)- $\alpha$-L- $\quad$ rhamnopyranoside (1) in cancer cells.

\section{Anti-oxidation activity}

Antioxidants are used in cosmetics, food, and medicine against cellular free radicals and reduce metal ions. We examined the two extracts anti-oxidation activity by DPPH and reducing power assays. In the previous study, the vitamin $\mathrm{C}$ was used as positive control compared with flavonoids compound [10]. As shown in Table 2, kaempferol-3-O$(2 ", 4$ "-di-E-p-coumaroyl)-a-L-rhamnopyranoside (1) has better radical scavenging activity $(65.21 \pm 0.80 \%)$ than kaempferol-3-O-(3",4"-di- $E$ $p$-coumaroyl)- $\alpha$-L-rhamnopyranoside $(17.40 \pm 0.13 \%)(2)$ at the same dose. In the ferric reducing antioxidant power (FRAP) assay, the reducing power of the two compounds were examined compared with 3-tert-butyl-4-hydroxyanisole (BHA) and shown in Table 2. Based on the results, kaempferol-3-O-(2",4"-di-E-p-coumaroyl)- $\alpha$ L-rhamnopyranoside (1) has better reducing power than kaempferol3-O-(3",4"-di- E-p-coumaroyl)- $\alpha$-L-rhamnopyranoside (2).

\section{Discussion}

Previous studies, we have isolated many compounds from $C$. reticulatum Hayata. Among these compounds, butanolide isoobtusilactone A has many pharmacological activities including cell cycle arrest, apoptosis and reactive oxygen species (ROS) generation in cancer cells [11-15]. Studies have shown that flavonoids possess anti-oxidation, anti-cancer,

\begin{tabular}{|c|c|c|}
\hline Cell Line & $\mathbf{1}$ & $\mathbf{2}$ \\
\hline A549 & $5 \pm 0.42 \mu \mathrm{g} / \mathrm{mL}$ & $2.1 \pm 0.18 \mu \mathrm{g} / \mathrm{mL}$ \\
\hline NCI-H460 & $4.6 \pm 0.34 \mu \mathrm{g} / \mathrm{mL}$ & $1.6 \pm 0.09 \mu \mathrm{g} / \mathrm{mL}$ \\
\hline MCF-7 & $7.2 \pm 0.63 \mu \mathrm{g} / \mathrm{mL}$ & $3.9 \pm 0.31 \mu \mathrm{g} / \mathrm{mL}$ \\
\hline MDA-MB-231 & $8.4 \pm 0.82 \mu \mathrm{g} / \mathrm{mL}$ & $4.6 \pm 0.33 \mu \mathrm{g} / \mathrm{mL}$ \\
\hline
\end{tabular}

Data were expressed as a mean value of at least three independent experiments.

Table 1: The $\mathrm{IC}_{50}$ of kaempferol-3-O-(2",4"-di-E-p-coumaroyl)-a-L-rhamnopyranosid (1) and kaempferol-3-O-(3",4"-di-E-p-coumaroyl)- $\alpha$-L-rhamnopyranoside (2) in different cancer cell line. 
Citation: Liu CM, Yeh HC, Huang SC, Li CT, Chen CY (2015) The Antioxidation and Antiproliferation Activity of New Flavonoids from the Leaves and Stems of Cinnamomum reticulatum Hayate. Med chem 5: 064-066. doi:10.4172/2161-0444.1000244

\begin{tabular}{|c|c|c|}
\hline Compound & DPPH ( \% ) & reducing power \\
\hline $\mathbf{1}$ & $65.21 \pm 0.80$ & $0.136 \pm 0.01$ \\
\hline $\mathbf{2}$ & $17.40 \pm 0.13$ & $0.071 \pm 0.00$ \\
\hline Vitamin C & $100.00 \pm 0.00$ & - \\
\hline BHA & - & $0.306 \pm 0.05$ \\
\hline
\end{tabular}

Vitamin $\mathrm{C}$ was used as a positive control on DPPH assay at $100 \mu \mathrm{mole} / \mathrm{L} ; \mathrm{BHA}$ was used as a positive control on reducing power at $100 \mu \mathrm{mole} / \mathrm{L}$.

Table 2: DPPH radical scavenging activity (\%) and reducing power of two extracts kaempferol-3-O-(2",4"-di-E-p-coumaroyl)-a-L-rhamnopyranosid (1) and kaempferol3-O-(3",4"-di-E-p-coumaroyl)- $\alpha$-L-rhamnopyranoside (2) of $C$. reticulatum.

hepatoprotective, anti-inflammatory activities [6,7]. In the present study, we demonstrated that two flavonoids kaempferol-3-O-(2",4"-di-E- $p$ coumaroyl)- $\alpha$-L-rhamnopyranosid (1) and kaempferol-3-O-(3",4"-di-E- $p$ coumaroyl)- $\alpha$-L-rhamnopyranoside (2) have anti-oxidation and cytotoxic activity in cancer cells.

Flavonoids possess anti-oxidative effects as free radical scavengers and metal ion cheaters properties associated with the phenolic hydroxyl groups attached to ring structures. Intensity of the antioxidant activity of a flavonoid strongly depends on its chemical structure. There is a great deal of discussion and contradiction regarding the structure antioxidant activity relationships of flavonoids. However, it is wellaccepted that the antioxidant activity of flavonoids is markedly influenced by the number and position of hydroxyl groups on the $\mathrm{B}$ and $\mathrm{A}$ rings, and by the extent of conjugation between the $\mathrm{B}$ and $\mathrm{C}$ rings. On the basis of many previous and recent findings, it seems that favorable general structural requirements for effective radical scavenging and/or the antioxidative potential of flavonoids follow the famous three Bors' criteria:

a) The $o$-hydroxy structure in the B ring, which confers high stability to the flavonoid phenoxyl radicals via hydrogen bonding or by expanded electron delocalization; b) The $\mathrm{C} 2-\mathrm{C} 3$ double bond (in conjugation with the 4-oxo group), which determines the coplanarity of the heteroring and participates in radical stabilization via electron delocalization over all three ring systems; $c$ ) The presence of both 3-OH and $5-\mathrm{OH}$ groups for the maximal radical scavenging capacity and the strongest radical absorption (i.e., 1 and 2).

Taken these results together, the two flavonoids possess antioxidation and cytotoxic activity in the cancer cells. In the future, the exact mechanisms of anti-cancer activity of the compounds can be further examined.

\section{Acknowledgements}

This work was financially supported by the Ministry of Science and Technology of the Republic of China under Grant No. MOST 103-2320-B-242-001 (Chung-Yi Chen).

\section{References}

1. Sharma V, Rao LJ (2014) An overview on chemical composition, bioactivity and processing of leaves of Cinnamomum tamala. Crit Rev Food Sci Nutr 54: 433-448.

2. Jayaprakasha GK, Rao LJ (2011) Chemistry, biogenesis, and biological activities of Cinnamomum zeylanicum. Crit Rev Food Sci Nutr 51: 547-562.

3. Chen CY, Yeh HC (2011) A new amide from the stems of Cinnamomum reticulatum Hay. Nat Prod Res 25: 26-30.

4. Lin IJ, Lo WL, Chia YC, Huang LY, Cham TM, et al. (2010) Isolation of new esters from the stems of Cinnamomum reticulatum Hay. Nat Prod Res 24: 775-780.

5. Cheng MJ, Lo WL, Tseng WS, Yeh HC, Chen CY (2010) A novel normonoterpenoid from the stems of Cinnamomum reticulatum Hay. Nat Prod Res 24: 732-736.

6. Corcoran MP, McKay DL, Blumberg JB (2012) Flavonoid basics: chemistry sources, mechanisms of action, and safety. J Nutr Gerontol Geriatr 31: 176189.

7. Xiao ZP, Peng ZY, Peng MJ, Yan WB, Ouyang YZ, et al. (2011) Flavonoids health benefits and their molecular mechanism. Mini Rev Med Chem 11: 169177.

8. Yao LH, Jiang YM, Shi J, Tomás-Barberán FA, Datta N, et al. (2004) Flavonoids in food and their health benefits. Plant Foods Hum Nutr 59: 113-122.

9. Blois MS (1958) Antioxidants determination by the use of a stable free radical Nat 181:1199-1200.

10. Ding HY (2011) Extracts and constituents of Rubus chingii with ,1-diphenyl-2picrylhydrazyl (DPPH) free radical scavenging activity. Int J Mol Sci 12: 3941 3949.

11. Chen CY, Yiin SJ, Hsu JL, Wang WC, Lin SC, et al. (2012) Isoobtusilactone A sensitizes human hepatoma Hep G2 cells to TRAIL-induced apoptosis via ROS and CHOP-mediated up-regulation of DR5. J Agric Food Chem 60: 3533-3539.

12. Chen CY, Chen CH, Lo YC, Wu BN, Wang HM, et al. (2008) Anticancer activity of isoobtusilactone A from Cinnamomum kotoense: involvement of apoptosis, cell-cycle dysregulation, mitochondria regulation, and reactive oxygen species. J Nat Prod 71: 933-940.

13. Liu TZ, Cheng JT, Yiin SJ, Chen CY, Chen CH, et al. (2008) Isoobtusilactone A induces both caspase-dependent and -independent apoptosis in Hep G2 cells. Food Chem Toxicol 46: 321-327.

14. Kuo PL, Chen CY, Hsu YL (2007) Isoobtusilactone A induces cell cycle arrest and apoptosis through reactive oxygen species/apoptosis signal-regulating kinase 1 signaling pathway in human breast cancer cells. Cancer Res 67: 7406-7420.

15. Chen CY, Liu TZ, Chen CH, Wu CC, Cheng JT, et al. (2007) Isoobtusilactone A-induced apoptosis in human hepatoma Hep $\mathrm{G} 2$ cells is mediated via increased NADPH oxidase-derived reactive oxygen species (ROS) production and the mitochondria-associated apoptotic mechanisms. Food Chem Toxicol 45: 1268-1276. 